Article

\title{
Challenging Racist Violence and Racist Hostility in 'Post-Racial' Times: Research and Action in Leeds, UK, 2006-2012
}

Ian Law ${ }^{1,2}$, Jenny Simms ${ }^{3}$ and Ala Sirriyeh ${ }^{4}$

${ }^{1}$ School of Sociology and Social Policy, University of Leeds, Leeds, LS2 9JT, UK; E-Mail: i.g.law@leeds.ac.uk

${ }^{2}$ Centre for Ethnicity and Racism Studies, University of Leeds, Leeds, LS2 9JT, UK

${ }^{3}$ Independent Researcher; E-Mail: jennysimms44@hotmail.com

${ }^{4}$ School of Social and International Studies, University of Bradford, West Yorkshire, BD7 1DP, UK;

E-Mail: a.sirriyeh@bradford.ac.uk

\section{How to Cite this Article}

Law, I., Simms, J., \& Sirriyeh, A. (2013). Challenging Racist Violence and Racist Hostility in 'Post-Racial' Times: Research and Action in Leeds, UK, 2006-2012. Social Inclusion, 1(1), 13-20.

\section{Acknowledgement}

This Article was published by Librello, Social Inclusion's former publisher.

\author{
About the Journal \\ sion worldwide. \\ www.cogitatiopress.com/socialinclusion \\ Editor-in-Chief \\ Professor Ulf R. Hedetoft, Faculty of Humanities, University of Copenhagen, Denmark \\ Mr. António Vieira, Social Inclusion, Cogitatio Press, Portugal
}

Social Inclusion is a peer-reviewed open access journal which provides academics and policy-makers with a forum to discuss and promote a more socially inclusive society. The journal encourages researchers to publish their results on topics concerning social and cultural cohesiveness, marginalized social groups, social stratification, minority-majority interaction, cultural diversity, national identity, and core-periphery relations, while making significant contributions to the understanding and enhancement of social inclu- 


\title{
Challenging Racist Violence and Racist Hostility in 'Post-Racial' Times: Research and Action in Leeds, UK, 2006-2012
}

\author{
Ian Law ${ }^{1,2, *}$, Jenny Simms ${ }^{3}$ and Ala Sirriyeh ${ }^{4}$ \\ ${ }^{1}$ School of Sociology and Social Policy, University of Leeds, Leeds, LS2 9JT, UK; E-Mail: i.g.law@leeds.ac.uk \\ ${ }^{2}$ Centre for Ethnicity and Racism Studies, University of Leeds, Leeds, LS2 9JT, UK \\ ${ }^{3}$ Independent Researcher; E-Mail: jennysimms44@hotmail.com \\ ${ }^{4}$ School of Social and International Studies, University of Bradford, West Yorkshire, BD7 1DP, UK; \\ E-Mail: a.sirriyeh@bradford.ac.uk \\ * Corresponding Author
}

Submitted: 13 February 2013 | In revised form: 18 March 2013 | Accepted: 10 April 2013 |

Published: 22 April 2013

\begin{abstract}
Despite increasing understanding of, information about and official commitment to challenge these patterns, racist hostility and violence continue to have an enduring presence in urban and rural life in the UK. This indicates the paradoxical nature of this racial crisis and challenges for antiracism as a political project. This paper charts how these issues play out at the local level through an examination of a five year process from problem identification through to research, response, action and aftermath from 2006 to 2012 in the city of Leeds, UK, with a focus on two predominantly white working class social housing estates in the city. We explore how embedded tensions and antagonisms can begin to be challenged, while examining how the contemporary climate of austerity and cuts in services, together with prevailing post-racial thinking, make the likelihood of such concerted action in the UK increasingly remote.
\end{abstract}

Keywords: antiracism; housing; racist harassment

\section{Introduction}

Racist hostility and violence continue to be a significant and enduring dimension of both urban and rural life both in the UK and Europe despite increasing understanding of, information about and official commitment to challenge these trends. This indicates both challenges for antiracism as a political project and the paradoxical nature of this racial crisis. In this paper we chart how these issues play out at the local level through revisiting a study conducted in 20062007 in two predominantly white working-class social housing estates in the city of Leeds, UK. Leeds is a large city in the north of England with a population of

(C) 2013 by the authors; licensee Librello, Switzerland. This open access article was published under a Creative Commons Attribution License (http://creativecommons.org/licenses/by/3.0/). 
751,500 at the 2011 Census. The paper begins by outlining the background and context in which this study was commissioned and the methodology we used. The paper then discusses the study findings through exploring victims' experiences of racist hostility, explanations for the hostility and violence and, finally, the responses to this hostility. In the final section we draw on the aftermath of the report's presentation to local stakeholders and a recent return research visit in 2011-2012 to the original study site, during which we interviewed staff members from key local agencies to review impact and responses since the original study took place.

This paper positions evidence of declining action and commitment in the context of the 'post-racial' [1]. In this era, commitment and action by public agencies is declining as there is a denial and silencing of the significance of race and racism in the lived experiences of minorities and these issues are displaced from the political agenda [2]. A recent research report which examined the response of public authorities' commitment and action to eliminate targeted harassment and violence in the UK has confirmed that decreasing numbers of authorities are taking action, working on prevention, supporting victims and working with perpetrators [3].

\section{The Leeds Study}

The research study conducted in 2006-2007 arose from concerns expressed by local area housing management staff about increasing racial harassment. A number of recent serious cases and race hate in parts of this area of Leeds had also been identified as a key concern in a city wide report on hate crime in November 2006. This report concluded that,

'Empirical evidence has clearly identified that on certain estates on specific streets there effectively exist 'no-go areas' for black and minority ethnic families due to the level of intimidation and harassment families have received' ([4], p. 5).

One hundred sixteen racist incidents were recorded by Leeds City Council, and a similar high number were recorded by the Police and Leeds Racial Harassment Project in 2005/06 in the local area [5]. These incidents included firebombing, racist graffiti, racist abuse, property and vehicle damage, smashed windows, throwing bricks, assault, setting fires, threats and intimidation, and repeated racist victimisation by groups of local young people. This was recognised by the Council as an increasing trend of both organised and spontaneous racist victimisation of black, Asian and minority ethnic (BAME) families. Understanding the drivers of local hostility and antagonism in the area, and understanding the problems which newcomers, and in particular BAME households, experienced on the estate was seen as a key objective.
This area is dominated by social housing (mainly council owned) where unemployment and benefit dependency have increased since the loss of manufacturing jobs in the 1970 s and 1980s. A sustained programme of intensive neighbourhood management had also been in operation in this locality which had highlighted wider problems of racist hostility and racist victimisation. The historical and continued formation of predominantly white council estates in this area, due to a specific range of processes, had recently been subject to change due to an increase in lettings to BAME tenants. This was facilitated by the introduction of more 'customer-focused' housing lettings systems and lettings to refugees. Historical patterns of housing allocation, racial discrimination, segregation of 'problem' families and self-segregation/avoidance choices by both BAME and white households led to the production of an area which was almost exclusively white. The impact of housing renewal and allocation policy involved initial re-housing of predominantly white households from slum clearance into the area when it was built [6]. Long-standing reticence to offer housing to black and minority ethnic households in areas outside the main areas of black and minority ethnic settlement in the city, combined with the 'dumping' of white households with multiple problems in the area produced a context which reinforced ethnic and racial divisions in housing choices $[7,8]$. Long-standing perceptions and experiences of high levels of racial hostility in this area and other parts of Leeds had been a significant constraint on the housing choices of many BAME households [9].

The introduction of choice-based lettings ( $\mathrm{CBL}$ ) systems together with improving agency responses to racist violence had in recent years begun to improve opportunities for housing choice. CBL allows housing applicants to view details on, choose between, and apply (or 'bid') for currently available-to-let properties. This contrasts with traditional housing allocation systems where applicants are normally faced with only a choice of whether to accept or reject a property deemed 'suitable' by a social landlord. In this way, $\mathrm{CBL}$ aims to transform the letting of social housing from a producer-driven function to a consumer-led service. Originating in the Netherlands, the application of CBL in Britain was given substantial impetus by the English Housing Green Paper of 2000 [10]. This backed $\mathrm{CBL}$ as empowering housing applicants by enabling them to play a direct role in selecting their future home.

Government targets aimed to extend $\mathrm{CBL}$ to all local authorities in England by 2010, following the introduction of such schemes in 27 local authority areas during 2001-2003. An evaluation of the impact of these programmes found that in Leeds, perhaps even more than in towns like Bolton and Bradford, minority ethnic social renters were spatially concentrated in 2001, with $52 \%$ living in three of the council's 29 housing management administrative 
areas [11]. The reduction of ethnic concentration of BAME lettings was a direct consequence of the introduction of $\mathrm{CBL}$ in Leeds, with the proportion of these lettings in 'areas of concentration' falling from $47 \%$ pre-CBL to only $27 \%$ post-CBL. Similarly lettings to BAME households in areas of low black and ethnic minority concentration, including this area, had doubled overall. Other factors which may have played a role in this process of 'de-segregation' included the Immigration and Asylum Act 1999 from which a dispersal programme was established whereby people claiming asylum were dispersed to live in allocated housing in regions outside London and the South East of England [12].

In some cases this process of 'de-segregation' has involved offering and letting properties to households who are immediately at high risk of racist violence, as our study found. In response, amendments to CBL were made to give back some additional scope for managerial action including risk assessment procedures. This meant housing staff making a judgement about whether it was safe for a black or minority ethnic family to move into a particular property. It was clear that many such families were prepared to face such risks because of the insecurity and poor quality of their previous housing circumstances. Increasing ethnic diversity of households is certain to continue despite the risk of violence due to pressing housing needs, reduction in racial discrimination by housing institutions and greater opportunity for household choice. In this dynamic context, effective and fair management of the needs and concerns of all households is needed.

Leeds City Council first adopted a Racial Harassment Policy in 1986. Evidence from the early years of that policy showed a sporadic pattern of racist violence being reported across most inner and outer estates and areas, which could not be easily explained in terms of competition, territorialism or activities of extreme right groups. Twenty years later, levels of reported incidents of race hate in Leeds were between 4,000 and 5,000 across the city and indicated the durability, geographical spread and significance of such violence. Reported incidents had hugely increased during this period which confirmed significant improvements in public reporting, staff awareness and agency recording practices. However, reported incidents were acknowledged to be a fraction of the total number, with real levels of race hate incidents likely to be upwards of 10,000 per year. Factors which strengthen the bonds between families, including changing economic opportunities and isolation from social networks outside the local area, can strengthen mobilisation to respond to external threats and dangers. Strong communities may often be highly exclusionary. A key to understanding how this process works was to examine local norms, values and sanctions to conform operating across a range of networks including families, friends/peer groups and other informal forms of association.

Our research examined perceptions expressed by victims of racist hostility, other residents and staff from key agencies in the two housing estates in Leeds. Interviews and focus groups were completed with 103 research participants. In the first phase of data collection (late December 2006 to January 2007) we interviewed 20 'key informants', comprising voluntary and public sector workers with responsibility for the area. Through this initial work we aimed to build up an informed picture of both the history and context of racial tension in the area and agency perspectives. This was in order to situate the incidence of racial harassment and victimisation through accessing 'expert narratives'. This data is representative of the perspectives of people working to tackle and explain racism within the community. In addition a further seven key informants were interviewed at later stages of the project.

From January to March 2007 we conducted fieldwork with 11 people who, along with other members of their families, had been identified as victims of racial harassment on the estate. These interviews did not always take place on the estate as several people had moved away from the estate and been re-housed. At the time of writing our 2007 report, five families had moved out of the area and were living elsewhere, two of these in temporary accommodation. Three were still living in the area, but had applied to move, and three were living in the area and planning to stay.

Between March and June 2007 we undertook semistructured interviews and focus groups with 65 residents on the estates. The majority of interviews took place in resident's homes, although two chose to be interviewed at a local housing office. This interview based approach was complemented by the writing of extensive field-notes. These documented meetings, contacts and conversations in the field. In total 45 residents were interviewed, together with four focus groups with 20 young people who were residents on the estate.

A local election took place within the period we were carrying out the research. The British National Party (BNP) was actively and visibly campaigning in the area. Commenting on this often gave us a route into tackling the subject of racism. As such, the research can be situated within a particular temporal context, within which the politics of race had some prominence and salience for some people. It was notable that many people did not hold racist views, contested racism or were unaware of the problem. There was a complexity and micro-geography of who appeared to be concerned about race and why. It must also be noted that participants often brought up the topic themselves in relation to housing allocation policy and repairs. We found it productive to find how people themselves introduced the topic offering them prompts around areas that we learned, were 'catalysts' 
for such a discussion such as the local election, housing, newcomers' experiences, dominant families on the estate and crime and anti-social behaviour.

In 2011-2012 we conducted semi-structured interviews with six key informants from agencies working in these estates to assess the impact of the 2007 study and review responses to racist hostility in the area since the original study had taken place, including changing circumstances. These perspectives are discussed in the section on responses later on. First, we explore the 2007 study findings on victims' experiences of racist hostility and explanations for the hostility.

\section{Victims' Experiences of Racist Hostility}

Evidence from victims identified the immediate and escalating levels of racist violence they experienced. The routine 'everyday' nature of this hostility and violence included: verbal abuse, graffiti, eggs thrown at houses, cars burnt out, physical assaults on children and adults, and petrol bombing. Most respondents experienced repeat or continuous racist harassment while living on the estates, often with similar patterns of escalation until they were forced to move away. Harassment often began with verbal abuse and actions such as eggs being thrown and escalated to more severe forms of violence and harassment. Families commented on the routine and everyday nature of harassment and, in this context, they felt it was too difficult to report all the 'incidents'.

Few respondents felt able to continue living in the area after these experiences and many compromised on the quality of their accommodation when relocating to safer housing. Four of the five families who were no longer living in the area had been relocated in emergency circumstances due to violent attacks on their property in combination with other incidents. One of these families had to be escorted from the property by the Police to ensure their safety when a large group of people had gathered outside their house. As a result, victims often felt isolated in these communities and constantly under siege.

Oh I would say it is like a jail. It is like you are living in jail (Black African female resident).

People [in the local area] are very united. They are racist. They come as a group because the youths they come together in an area...even the elders there support the youths (Black African female resident).

A variety of strategies were deployed in response to these experiences including avoidance and changes to daily routines, negotiation, trying to 'keep neighbours onside' and late reporting of cases [13]. The impact on families included deterioration in physical and mental health, markedly so for children. Significant difficulties were experienced in obtaining re-housing following racist harassment. Victims described widespread hostility in this area combining overt aggressive racism, particularly from children and young people, with more covert everyday racist talk from older people. Although there was also recognition of some positive interactions with some neighbours and other residents. They identified a serious lack of awareness and exposure to cultural diversity in the local community. They were also intimidated due to BNP activities in the area. Victims expressed some positive comments about the support from individuals from agencies including Housing, Police, Victim Support and Leeds Racial Harassment Project (now Stop Hate UK), but were critical of the ability of agencies to respond effectively given the scale of widespread racist hostility and the weakness of enforcement processes. There was room for significant improvement in many aspects of work with victims including information and advice, casework support, re-housing, enforcement and prevention.

\section{Understanding Racist Hostility}

The drivers of racist hostility were found to include resentment of BAME families' ability to access social housing, jealousy of lifestyle and possessions, and perceptions of unfair preferential treatment $[14,15]$. Competition-based racist hostility in relation to housing and employment was strongly voiced [16]. This was compounded by everyday racist talk/hearsay, related misinformation, and the denial of racist intent. One centrally important contextual factor was community self-policing: power and mobilisation of local family and community networks to enforce hostility, drive families out and maintain an atmosphere of fear and intimidation. There was an instrumental promotion of racist hostility where it was seen to be useful to achieve family, community or criminal goals. Several tensions in the area were linked to very narrow and specific social and geographic boundaries of trust and safety, and racisms on this estate were linked to fear of the 'other' and fierce allegiance to those who are close to oneself.

Poverty, abandonment and disempowerment were often articulated through racist hostility. Mistrust of authority and feelings of disengagement had led to community self-regulation practices that were exclusionary and defensive. Narratives of neglect and lack of care were strongly expressed together with some strong sense of community pride and affection for the area. Hostility to public agencies, and an embattled sense of political and social abandonment and isolation with local values of 'toughing it out' and 'looking after your own' were frequently expressed. Therefore, for many households in these areas racist hostility met a test of practical adequacy and sensemaking and fitted with core norms and values.

Racism in this locality took a number of forms, was 
expressed in a variety of ways and also intersected with a multiplicity of other bitter resentments and emotions related to class, poverty and gendered identities. It was often hard for both residents and researchers to separate issues of racism from other common practices of resentment, exclusion and suspicion within estate life. People on the estate were not always explicitly racist in terms of skin colour, but drew upon spectra of belonging and entitlement that factored in class, family, affiliation, heritage and levels of contribution to estate life. Race difference was often used as a channel for rage, anger and disaffection, as an expressive tool, but not always the sole motivation. This helped to account for the high level of denial, distancing and justification expressed in relation to racism. Some of the more severe racist incidents on the estate were precipitated or triggered by noise nuisance, alcohol, adjunctive traffic incidents/accidents and unsociable hours.

Black African families were highly visible key targets of racist hostility. Catch-all terms such as 'Kosovan' and 'asylum-seeker' were also used in labelling households as problematic and for targeting hostilities. People with southern English accents, people in paid employment and Eastern Europeans had also been targets of harassment. An important aspect of our research was consultation with local politicians. In a 2012 interview with us, the local Labour MP, Rt. Hon Hilary Benn MP for Leeds Central confirmed the complications of the locality.

It is very hard to believe until you experience it, the culture of the two estates is that they felt detached from the prosperity of the city and this, in turn, bred resentment. We had such problems; the two estates were separated by a stretch of grass and so insular were the attitudes of some on the estate that those from the other estate were regarded as foreigners never mind those from 5000 miles away [17].

Lastly, the significant role of the BNP was examined showing how their message of representation of the excluded working classes tied in with local understandings and denials of racism, while undeniably racialising pre-existing resentments [18]. This was again confirmed by the local MP:

Sometimes the Labour Party, nationally, finds it hard to talk about race and immigration so when I am on the doorstep, talking to constituents, I often hear "You don't want to hear this" or "You don't want to talk about this". Well, we are done for if people think we don't want to talk about it [17].

Racist values were being passed on across generations, both within families on the estate and through other informal contact between children, young people and adults. Large groups of young people congregating in one area were often labelled as 'gangs' and subsequently many accounts of racist hostility were linked to their presence. However, interventions aimed primarily at young people did not address the role of parents and other adults who were involved in inciting racist behaviour and the wider community was often complicit in its inaction and protection of perpetrators. It emerged from our focus groups with young people that they were aware from school teachers, the Police and youth workers that expressing racist views was deemed inappropriate or wrong. However, further exploration of the issues with the young people led to an understanding that some young people did hold essentially racist views, often based on fear, jealousy and perceived unfair preferential treatment.

It's because the Council won't let any of the white people move in to houses because they're giving them to all the foreigners. My aunt waited three years for a house and they gave it to a pair of Kosovans (White young male, age 16).

This finding is also reflected in recent research in the West Midlands [16] which argues that white working class racialised opinions should be seen in the context of people feeling the effects of neighbourhood loss, political disconnection and competition for scarce resources.

\section{Responding to Racist Hostility}

The need for an improvement in agency responses was recognised by many representatives from local agencies. Poor levels of service, poorly implemented policy, poor perceptions of services and a strong desire for more effective work with local communities were powerfully stressed:

The level and adequacy of support for victims and families suffering from racist victimisation is appalling and services are very fragmented (Customer Services Manager).

How do you deal with a community who feel that they have so much anger that they have to attack somebody?...What is lacking is engagement with communities...getting them to change, support and befriend people (Principal Hate Crime Officer).

Our report strongly supported the general thrust of these views and sought to show how greater understanding of both the impact of racist harassment on victims and the complex ways in which racist hostility works in local communities requires a rethinking and a renewal of policy and practice in this field. To facilitate this process a second report [19] was produced which examined a wide-ranging set of evidence and interventions and proposed the establishment of an explicit 'racism reduction' strategy in Leeds.

In examining the fit between this racism reduction agenda and local Race Hate Crime Strategy in Leeds it 
was clear that there were many gaps including a failure to develop preventative community-based interventions. On 31 January 2008 both these reports were presented to the board of Safer Leeds [20]. This was chaired by Councillor Les Carter, Conservative councillor for Adel and Wharfedale constituency in the city. His response to these two reports indicated that there was no point in carrying out such research, and that what was happening in this area of Leeds was purely local people being concerned about local housing in their area. This view took shape in new plans to reserve a quarter of council housing in Leeds for 'local' people, about 15,000 properties. Councillor Carter defended this saying, 'It is nothing to do with immigration', but, instead, a response to 'massive complaints' from 'people who seem to feel they are being moved away from their families. It has been a really big issue for a long time' [21]. This dismissal of the importance of engaging with racist hostility, racist victimisation and racist violence was not however shared by official representatives from public service agencies, including Safer Leeds itself, with a particular concern expressed that action needed to be swiftly taken to improve support for children who had been victims of racist violence.

The positive response was also evident through the commitment of key officers in relevant local agencies, and their work in the context of the newly established local Hate Crime (HC) Group. The lack of local coordination in response to racist incidents and strategic leadership had produced a sense of frustration. This was combined with a sense of being overwhelmed by the rising number of incidents and the strength of local hostility. The HC Group provided a means to move forward, developing a strategic approach and taking on board the range of recommendations made by the two research reports $[19,22]$. In particular, there was focus on generating wider community and institutional commitment to tackle racist violence. 26 BAME families who had suffered from racist harassment also sent a petition to the local MP, and highlighted their key concerns to the $\mathrm{HC}$ Group. These concerns included problems with communication and response from the Police, lack of positive action against perpetrators and lack of information from social housing managers about the level of racist incidents prior to taking on their tenancies.

This was contradicted by the local MP who believed that the two estates were less environmentally hostile now than they had been and attributed this to positive enforcement action by local services, the ALMO [23], the Police, the increased security and the threat of civil penalties.

I had no doubt, as the local MP, that the police did everything they could to eradicate the racist violence on the estate and to prosecute. The ALMO did all they could to find perpetrators and even seconded a member of staff to the community action group. Under no circumstances did I feel that either of them were complicit in the aggression towards asylum seekers and new families on the estate, they were very troubled by it. They were desperate to catch people in the act. [17]

Fifteen specific initiatives were taken by local agencies following on from this process and these were reviewed by Safer Leeds in 2009. Use was made of professional witnesses who operated undercover to identify race hate perpetrators, but with only limited evidence gathered and little enforcement action. Three arrests were made and there has been a reduction in race hate crimes in the locality, but this has also resulted from the cumulative impact of this and other interventions. Installation of fireproof letterboxes in properties at risk of attack has led to a significant reduction in related arson attacks and has been positively received by BAME residents. The education package associated with the 'Show Racism the Red Card' antiracist football based campaign, which has been put in place in local schools, has produced both a positive reaction from pupils and a poster campaign in the local area. Associated with this, has been the work with local clusters of schools to implement the Stephen Lawrence Education Standard, which embeds attention to race hate in the curriculum and the schooling context. Stop Hate UK (SHUK) has also held workshops both in local schools and with the local Youth Inclusion Project on race hate.

A Section 30 dispersal order giving the Police powers to disperse groups of two or more young people was granted from November 2007 to April 2008 and seems to have been one of the key factors in reducing levels of severe, threatening racist incidents, but may only have led to a displacement of tensions elsewhere. The local Women's Group developed productive face-to-face interaction with a refugee women's group through participation in a range of joint activities with positive feedback from both groups. The inclusion of black and minority ethnic representatives in the formation of a new residents' group also indicates a positive step forward in building intra-community cooperation. The establishment of scrutiny panels involving residents and multi-agency risk assessment groups to discuss cases of hate crime and improve victim support and action against perpetrators have both been reported as improving the confidence of local residents in the services provided by local agencies in this field. Implementation of swift initial response visits to victims of racial violence by an outreach worker and the Police have also assisted in this process.

By the autumn of 2008 this work was having a significant impact in reducing recorded racist incidents, with, for example, 27 incidents reported in October 2007 and zero in October 2008, improving success in detection rates and targeted enforcement activity and in improving residents' perceptions of safety. Yet there 
remains a core presence of strong racist hostility amongst some families and amongst some young people on these estates and there is, therefore, a significant threat of further harassment and violence.

In our 2011-2012 interviews it was acknowledged by the officer who had been in charge of the local Hate Crime Group at the time that our 2007 research reports had 'made a tremendous impact in raising awareness and empowering key individuals to act' and that there had been a major change in the local environment from one where black and minority ethnic families were routinely 'burnt out, beaten up and hounded out of the estate' to one where incidents continued, but were much less severe.

The most recent monitoring information confirms that there have been six incidents in a three month period in 2011 compared to approximately that number in one week in 2007. One main perpetrator is currently serving a three year sentence, and three extreme-right organisers who lived on the estate in 2007 have since moved/been moved out from this area. Hence, while in the May elections in 2008 many British National Party placards were in evidence in residents' front gardens across the estate, during the elections in May 2010 and May 2011, together with local BNP candidates, these had disappeared. While the successful criminal prosecution of individuals and action against extreme-right organisers was seen as having had an impact in small localities, an overemphasis on crime prevention, extremist ideologies and the role of particular individuals can risk the neglect of wider, underlying and durable experiences of racism. These strategies illustrate Lentin and Titley's ([2], p. 169) suggestion that race is buried or made invisible, because 'racism is understood as an irrational attribute or behaviour', an irrational sentiment exhibited by extremist individuals and, therefore, 'it has diminished purchase in a social vision that places rational and autonomous actors centre stage'.

While there were some positive reports of changing circumstances and action, there were also indications of further setbacks and challenges. The recent closures of a 'One Stop' shop and the local leisure centre, which was used by a variety of agencies and community groups, have reduced the already very limited services available on the estate and are likely to contribute to increased feelings of abandonment and neglect among local residents. These feelings were part of the complex set of factors which had led to a rise in resentment and hostility to others back in 2006-2007. Cuts were impacting directly on some support services for victims, for example the halt in funding for the support team operating from Stop Hate UK in Leeds, although other support services for victims were continuing to operate and funding had been maintained.

There was also recognition that the climate amongst local agencies across Leeds in 2011-2012, in relation to racist hostility and violence, was still one of denial, or 'racism fatigue', with a move to deny explicitly racist elements of incidents and move away from the language of 'race' through responses such as 'it's all just ASB' (anti-social behaviour), and the incorrect 'branding' of racism as a 'cohesion issue'. This was partly because this was seen as a 'job done'. The move away from a focus on racist violence to hate crime generally was also seen as indicative of this wider shift in agency perceptions. The rebranding and denial of racism characterises the 'post-racial' contemporary, where the terms of race have 'evaporated' and race is 'buried, alive' $[1,24]$. In this context, where race is silenced, privatised and removed from political agenda Kapoor ([25], p. 1) suggests, 'any progressive measures using race for the purposes of anti-racism fade from view.' Despite these factors, there was still evidence that a strong commitment to tackling racist incidents was a mainstream professional value amongst a range of staff from local agencies.

\section{Conclusion}

The ambivalent trends in responses to racist violence highlighted in the Leeds context are glocalised trends of today's 'post-racial' times, where there has been a wider shift from the politics and law of identities to the politics and law of human rights [26]. The logics of the post-racial incorporate a denial of the contemporary significance of racism and global racialisation beneath the rhetoric of liberal democracy, individualism, meritocracy and progress. In the UK 89 people have lost their lives in attacks with a racial element since the murder of Stephen Lawrence in 1993, and racist attacks regularly take place on the street, in people's homes, in taxis and taxi offices, in takeaways, restaurants, pubs and bars, as well as shops and religious institutions [27]. This is hardly a post-racist context. Even the US 'supercop' Bill Bratton, who recently advised Prime Minister David Cameron to assist in tackling gang crime and street crime in the wake of the recent riots in the UK, has acknowledged that it is not possible to arrest your way out of these problems and that underlying racial tensions need to be addressed [28]. Our message is a similar one, traditional criminal justice approaches have failed to reduce underlying racist hostility and associated racism. These embedded tensions and antagonisms can begin to be challenged, as this case study has demonstrated, and doing so can reduce such harassment and attacks. However, in the contemporary climate of austerity and cuts in services, together with prevailing post-racial thinking, the likelihood of such concerted action in the UK becomes increasingly remote. 


\section{References and Notes}

1. Goldberg DT. The post-racial contemporary. University of Seville, Seville, Spain; 2011. Unpublished public lecture.

2. Lentin A, Titley G. The Crisis of Multiculturalism: Racism in a neoliberal age. London, UK: Zed Books; 2011.

3. Chakraborti N, Gadd D, Gray P, Wright S, Duggan M. Public authority commitment and action to eliminate targeted harassment and violence. Manchester, UK: Equality and Human Rights Commission; 2011.

4. Leeds City Council. Tension Monitoring November 2006. Leeds, UK: LCC; 2006.

5. Leeds City Council. Recording and reporting hate crime in Leeds. Leeds, UK: LCC; 2006.

6. Duke C. Colour and Rehousing: A study of redevelopment in Leeds. London, UK: Institute of Race Relations; 1971.

7. Leeds City Council. Ethnic Monitoring of Housing Allocations. Leeds, UK: Dept. of Housing, Leeds City Council; 1985.

8. Law I, Davies I, Phillips D, Harrison M. Equity and Difference, racial and ethnic inequalities in housing needs and housing investment in Leeds. Leeds, UK: RAPP, University of Leeds; 1996.

9. Comrie J. The Housing Needs of African Caribbean Elders in Leeds [PhD thesis]. Leeds, UK: University of Leeds; 2007.

10. DETR. Quality and Choice: Decent Housing for All. London, UK: Department of the Environment, Transport and the Regions; 2000. Available from: http://www.gm1housing.co.uk/documents/DETR\%20 Quality\%20and\%20Choice\%20-\%20A\%20Decent\%2 0Home\%20for\%20All\%202000.pdf (accessed on 17 April 2013).

11. Pawson $\mathrm{H}$, Jones $\mathrm{C}$, Donohoe $\mathrm{T}$, Netto $\mathrm{G}$, Fancy C, Clegg S, Thomas A. Monitoring the Longer Term Impact of Choice Based Lettings. London, UK: Department for Communities and Local Government; 2006.

12. Asylum-seekers are not housed through mainstream social housing provision. It is only once people gain refugee status that they may access the $\mathrm{CBL}$ bidding process.
13. Chahal K, Julienne L. We Can't All Be White. York, UK: JRF; 1999.

14. Amin A. Ethnicity and the multicultural city: Living with diversity. Environment and Planning A. 2002;34(6):959-980.

15. Robinson D, Reeves K. Neighbourhood experiences of new immigration: Reflections from the evidence base. York, UK: JRF; 2006.

16. Beider $\mathrm{H}$. Community Cohesion: The views of white working class communities. York, UK: JRF; 2011.

17. Interview with the local Labour MP, Rt. Hon Hilary Benn MP for Leeds Central. 1 February 2012.

18. Rhodes J. The Banal National Party: The routine nature of legitimacy. Patterns of Prejudice. 2009;43(2): 142-160.

19. Law I. The Racism Reduction Agenda, building the framework, signposting good practice and learning the lessons. Leeds, UK: CERS; 2007.

20. Safer Leeds is a statutory partnership formed as a result of the Crime and Disorder Act 1998. The Safer Leeds Board is made up of representatives from the public, private and voluntary sectors. This is a consultative group that reviews the partnership plans and ensures that community consultation is coordinated effectively and reports to the citizens of Leeds.

21. Housing in Leeds. Big Issue. 27 May 2010.

22. Hemmerman L, Law I, Simms J, Sirriyeh A. Situating racist hostility and understanding the impact of racist victimisation in Leeds. Leeds, UK: CERS; 2007.

23. Arms Length Management Organisations are not-for-profit companies which provide housing services on behalf of a local authority.

24. Goldberg DT. The Threat of Race: Reflections on racial neoliberalism. Malden, MA, USA: Blackwell; 2009.

25. Kapoor $\mathrm{N}$. The advancement of racial neoliberalism in Britain. Ethnic and Racial Studies. 2011;1-19.

26. Hepple B. The New Single Equality Act in Britain. The Equal Rights Review. 2010;5,11-24.

27. Athwal HB. Racial Violence: The buried issue. London, UK: Institute of Race Relations; 2010.

28. UK riots: Police should tackle racial tension, says 'supercop' Bill Bratton. The Guardian. 13 August 2011. 